\title{
Geociências
}

\section{Interpretação das anomalias de potássio hidrotermal e parâmetro $F$ da região do Complexo Bossoroca, São Sepé, RS}

Márcio de Souza Soares

Doutorando LPM/DEMIN/UFRGS. E-mail: soaresm@ufrgs.br

Jair C. Koppe

Prof. Dr. LPM/DEMIN/UFRGS. E-mail: jkoppe@ufrgs.br

João Felipe C. L. Costa

Prof.Dr. LPM/DEMIN/UFRGS. E-mail: jfelipe@ufrgs.br

Silvia Beatriz Rolim

Prof. Dr.Dep.Geodésia/UFRGS. E-mail: silvia.rolim@ufrgs.br

\section{Resumo}

Diversas ocorrências de ouro estão localizadas na Seqüência Campestre do Complexo Bossoroca no Escudo Sul-Rio-Grandense. Nessa região foi realizado um levantamento aerogeofísico, onde mapas gamaespectrométricos $(\mathrm{K}, \mathrm{U}$, Th e contagem total) geraram informações sobre a geologia e possíveis alvos para futuras explorações minerais. Baseado nos métodos de potássio anômalo e parâmetro $\mathrm{F}$, esse trabalho apresenta o mapeamento de zonas hidrotermais associadas a mineralizações auríferas e a identificação de novas unidades geológicas para essa seqüência, estabelecendo-se critérios prospectivos para a exploração mineral regional.

Palavras-chave: processamento de dados aerogamaespectrométricos, exploração mineral de ouro, Complexo Bossoroca.

\begin{abstract}
Several gold occurrences are located in the Campestre Sequence of the Bossoroca Complex in the Shield Sul-Rio-Grandense. In this region, a magnetometric and gamaspectrometric airborne geophysical survey ( $K, U, T h$ and total counting) was carried out. Based on anomalous potassium and parameter $F$ this work presents the mapping of hydrothermal zones related to gold mineralization and the identification of new geological units for this sequence, establishing prospective criteria for regional mineral exploration.
\end{abstract}

Keywords: aerogammaspectrometric processing data, gold mineral exploration, Bossoroca Complex. 
Interpretação das anomalias de potássio hidrotermal e parâmetro F da região do Complexo ...

\section{Introdução}

Os métodos gamaespectrométricos têm um papel relevante na pesquisa de depósitos minerais auríferos associados a alterações hidrotermais. Para Fornazzari et al. (2001), a gamaespectrometria, aérea e terrestre, possibilita a identificação de áreas alteradas hidrotermalmente e exploração de suas relações com processos de mineralização de ouro e prata, além de metais base $(\mathrm{Cu}-\mathrm{Pb}-\mathrm{Zn})$, em vários ambientes geológicos.

Os dados utilizados nessa pesquisa são oriundos do Projeto Camaquã Área I (Jackson et al., 1973), realizado pela Companhia de Pesquisa de Recursos Minerais (CPRM) e pelo Departamento Nacional de Produção Mineral (DNPM) em convênio com a Texas Instruments Inc. As características desse aerolevantamento estão sumarizadas na Tabela 1.

Dada a relevância e dado o potencial econômico da região, efetivaram-se o processamento de dados aerogeofísicos gamaespectrométricos por meio de mapas de potássio hidrotermal e potássio anômalo, visando a elaborar mapas que trazem informações a cerca da quantificação e qualificação do Complexo Bossoroca em possíveis áreas com halos hidrotermais associados à mineralização aurífera.

A combinação das informações aerogeofísicas com informações da geologia regional e local relacionadas diretamente com as ocorrências auríferas auxiliou na definição dos principais controles dos depósitos auríferos, estabelecendo-se critérios prospectivos para a exploração mineral regional.

\section{Localização e geologia regional}

A área de estudo situa-se na região de São Sepé aproximadamente 400 km a oeste de Porto Alegre, na porção central do Estado do Rio Grande do Sul (Figura 1). A região é formada por rochas metavulcanossedimentares da Seqüência Campestre e por rochas metabásicas da Seqüência Arroio Lajeadinho, (Koppe et al., 1990), pertencentes ao Complexo
Bossoroca do Bloco São Gabriel do Escudo Sul-Rio-Grandense. O Bloco São Gabriel (Almeida \& Hasui, 1984), posiciona-se na Província Mantiqueira, que corresponde ao Sistema Brasiliano Sudeste, estendendo-se desde o Uruguai até a Bahia, com idades do Arqueano ao Eopaleozóico.

Diversas ocorrências auríferas identificadas na área estão inseridas na Seqüência Campestre, tendo por encaixantes principais metatufos. Os litotipos, constituintes dessa seqüência, podem ser agrupados da seguinte forma: rochas vulcanoclásticas, rochas epiclásticas e rochas químicas.

A seqüência Arroio Lajeadinho é composta predominantemente por xistos magnesianos, serpentinitos, metabasaltos, metagabros, metacherts, formações ferríferas bandadas, metatufos e outras rochas metassedimentares, principalmente metargilitos. Essa seqüência faz contato com a Seqüência Campestre por meio de uma falha transcorrente com movimentação dextral associada a uma zona de cavalgamento.

As características geoquímicas para o Complexo Bossoroca indicam baixos teores de potássio nas litologias vulcanoclásticas ácidas-intermediárias que compõem a Seqüência Campestre e a Seqüência Arroio Lajeadinho e baixos teores nas razões $\mathrm{K}_{2} \mathrm{O} / \mathrm{Na}_{2} \mathrm{O}$. A minera- lização aurífera na Seqüência Campestre favoreceu a formação de halos de alteração hidrotermal, principalmente de silicificação, carbonatização e cloritização, que promoveram forte dispersão dos dados químicos e de alterações hidrotermais e metamórficas, que provocaram modificações das características originais dos litotipos, afetando os elementos mais móveis como $\mathrm{Na}, \mathrm{K}, \mathrm{Ca}, \mathrm{Mg}$, Fe e Si.

Em relação aos dados geocronológicos da Seqüência Campestre e Arroio Lajeadinho, Remus (1998) obteve valores que indicam idades, do método U$\mathrm{Pb}$ em zircão via SHRIMP, de cristalização de $756 \pm 14$ Ma para os metadacitos da Formação Campestre, coincidindo com a idade obtida por Machado et al., 1990, e cerca de 700 Ma para o metamorfismo regional dinamotermal, que afetou essa seqüência. Dados recentes de $\mathrm{Sm} / \mathrm{Nd}$ para a Seqüência Arroio Lajeadinho indicam idades modelo de extração do manto de cerca de 1,7 Ga, onde evidências geoquímicas e isotópicas coincidem na indicação da presença de septos do embasamento transamazônico na região.

\section{Potássio Anômalo}

Considerando-se que o projeto $\mathrm{Ca}$ maquã foi realizado com espaçamento de linhas de vôo de $1 \mathrm{~km}$, foi estabelecida

Tabela 1 - Características do aerolevantamento realizado na região do Escudo Sul-riograndense.

\begin{tabular}{c|c}
\hline Métodos & Magnetometria Gamaespectrometria \\
\hline Contrato do período & 06 a 05/73 \\
\hline Intervalo (amostragem) & $1 \mathrm{~s}$ \\
\hline Altura de Vôo & $150 \mathrm{~m}$ \\
\hline Direção das linhas de vôo & $\mathrm{NW}-\mathrm{SE}$ \\
\hline Espaçamento das linhas de vôo & $1 \mathrm{~km}$ \\
\hline Direção das linhas de controle & $\mathrm{NE}-\mathrm{SW}$ \\
\hline Espaçamento das linhas de controle & $18 \mathrm{~km}$ \\
\hline Tempo de Integração Gama & $2 \mathrm{~s}$ \\
\hline
\end{tabular}


uma célula para malha regular com dimensão de 250 m, utilizando-se o algoritmo de interpolação de mínima curvatura.

No algoritmo desenvolvido por Pires (1995), a técnica para determinação do potássio anômalo baseia-se na teoria de que a relação potássio e tório é representada por uma função linear que passa pela origem. A inclinação da reta é determinada pela razão entre os valores das observações de potássio e tório, ao passo que o ponto de intersecção da reta no eixo $y$ está representado pelo fator $K y$. O procedimento é análogo para o comportamento do urânio. Para o potássio, temos a seguinte relação:

$$
K i=\left(\overline{K_{s}} / \overline{e T h} * e T h+K y\right.
$$

onde $K i$ é o potássio ideal, normalizado; $\bar{K}_{\mathrm{S}}$ é a concentração média de potássio; $\overline{e T h}$ é a concentração média de tório; $e T h$ é a concentração média do tório no ponto de amostragem e Ky é o desvio da reta em relação à origem.

Os desvios dos valores reais a partir dos valores ideais, calculados para cada ponto, foram obtidos usando a equação (2):

$$
K d=\frac{\left(\bar{K}-K_{i}\right)}{K_{i}}
$$

\section{Potássio anômalo para os dados regionais}

$\mathrm{O}$ algoritmo da técnica de potássio anômalo foi criado para suprimir contribuições primárias (devidas às rochas superficiais), fator que influencia a variação do rádio-elementos nas rochas. Com o seu uso não há a necessidade da separação de unidade geológica ou da digitalização do mapa geológico para que se estude cada resposta sobre seu teor litológico (Blum, 1999).

$\mathrm{Na}$ região que compreende o Complexo Bossoroca, verifica-se uma diversidade litológica em torno das Seqüências Arroio Lajeadinho e Campestre. Dessa forma, tório e potássio possuem

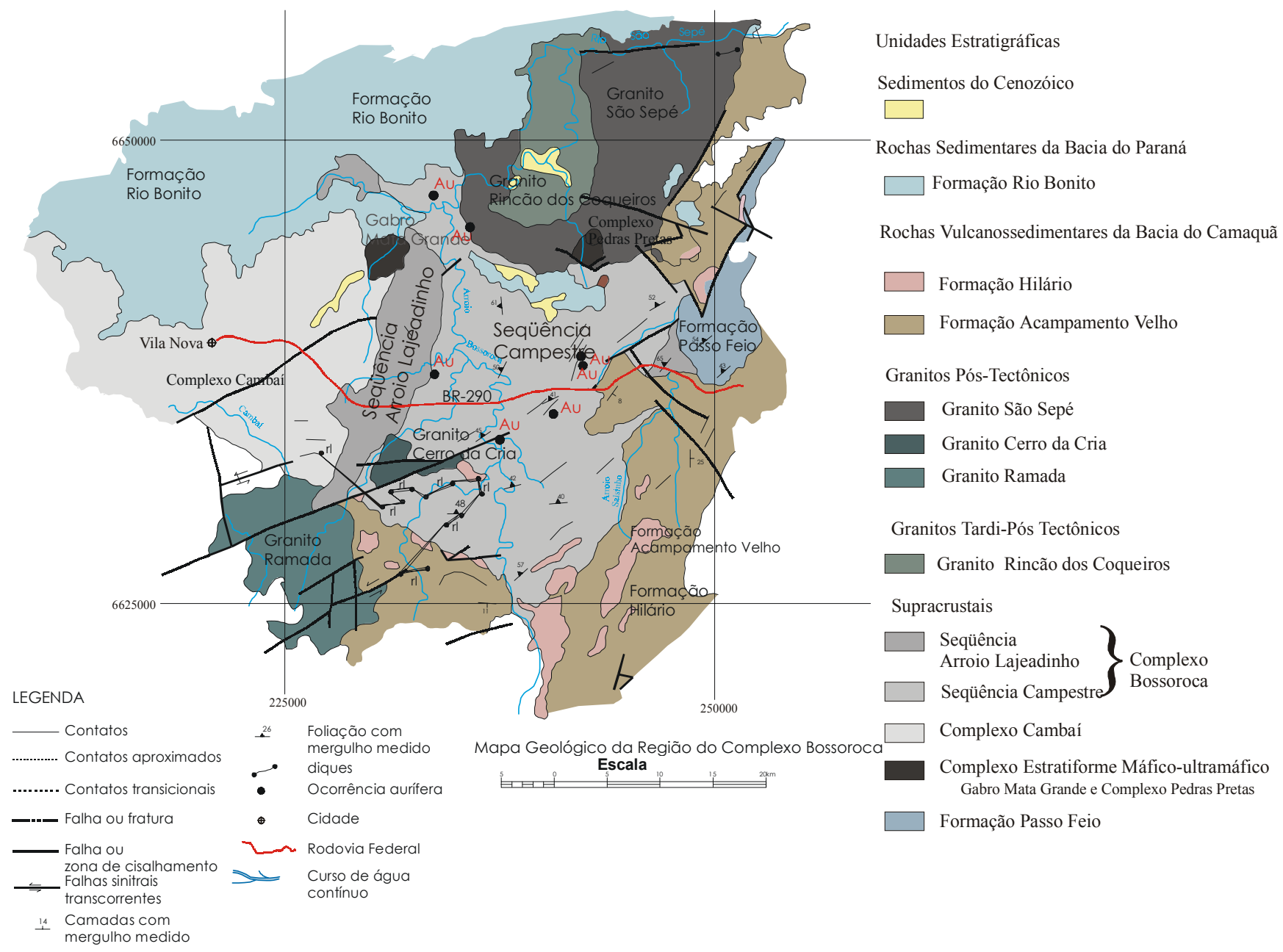

Figura 1- Mapa geológico da região do Complexo Bossoroca, modificado da Carta de Cachoeira do Sul (Porcher, 2000). 
uma relação não linear (Figura 2). A dispersão nos dados representa a variabilidade litológica na região do Complexo Bossoroca (Tabela 2), sendo difícil a separação entre zonas onde o potássio está relacionado a fenômenos litológicos das zonas que poderiam refletir processos de enriquecimento hidrotermal. Esse problema também é mostrado por Carvalho (1999) e Blum (1999) na região de greenstone belts de Pilar de Goiás e Guarinos, respectivamente.

A equação que melhor se ajustou aos dados regionais da Figura 2 é:

$K_{i}=3,18 * e T h-8,69$

Substituindo $K_{i}$ na equação (2) se obtém o valor do potássio anômalo para cada ponto (Figura 3).

\section{Parâmetro F}

Ostrovskiy (1973) estudou o antagonismo radioativo em paredes de rochas alteradas por processos metassomáticos. Esse autor salienta que, devido ao alto poder de migração do potássio em relação ao tório e ao urânio, é possível acúmulo de potássio em zonas hidrotermais. Ao contrário do tório e do urânio, o potássio está sempre na fase líquida da solução hidrotermal.

Prichystal e Gnojeck (1985), em estudos na mineralização de zinco, na República Tcheca, utilizaram o parâmetro F na identificação de encaixantes hidrotermalmente alteradas por anomalias potássicas. Efimov (apud Prichystal \& Gnojeck, 1985) também quantificou o parâmetro $F$, mostrando que valores acima de 1,2 ou 1,3 ppm são comuns em rochas não alteradas, ao passo que, em rochas alteradas, ele pode ser 2 ou, ainda, $5 \mathrm{ppm}$, excepcionalmente $10 \mathrm{ppm}$. Um mapa com parâmetro $F$ foi gerado para região do Complexo Bossoroca (Figura 4), salientando regiões com prováveis locais com potássio hidrotermal. A equação para o parâmetro $F$ é expressa na relação:

$F \equiv \frac{K \cdot e U}{e T h}=\frac{K}{e T h / e U}=\frac{e U}{e T h / K}$

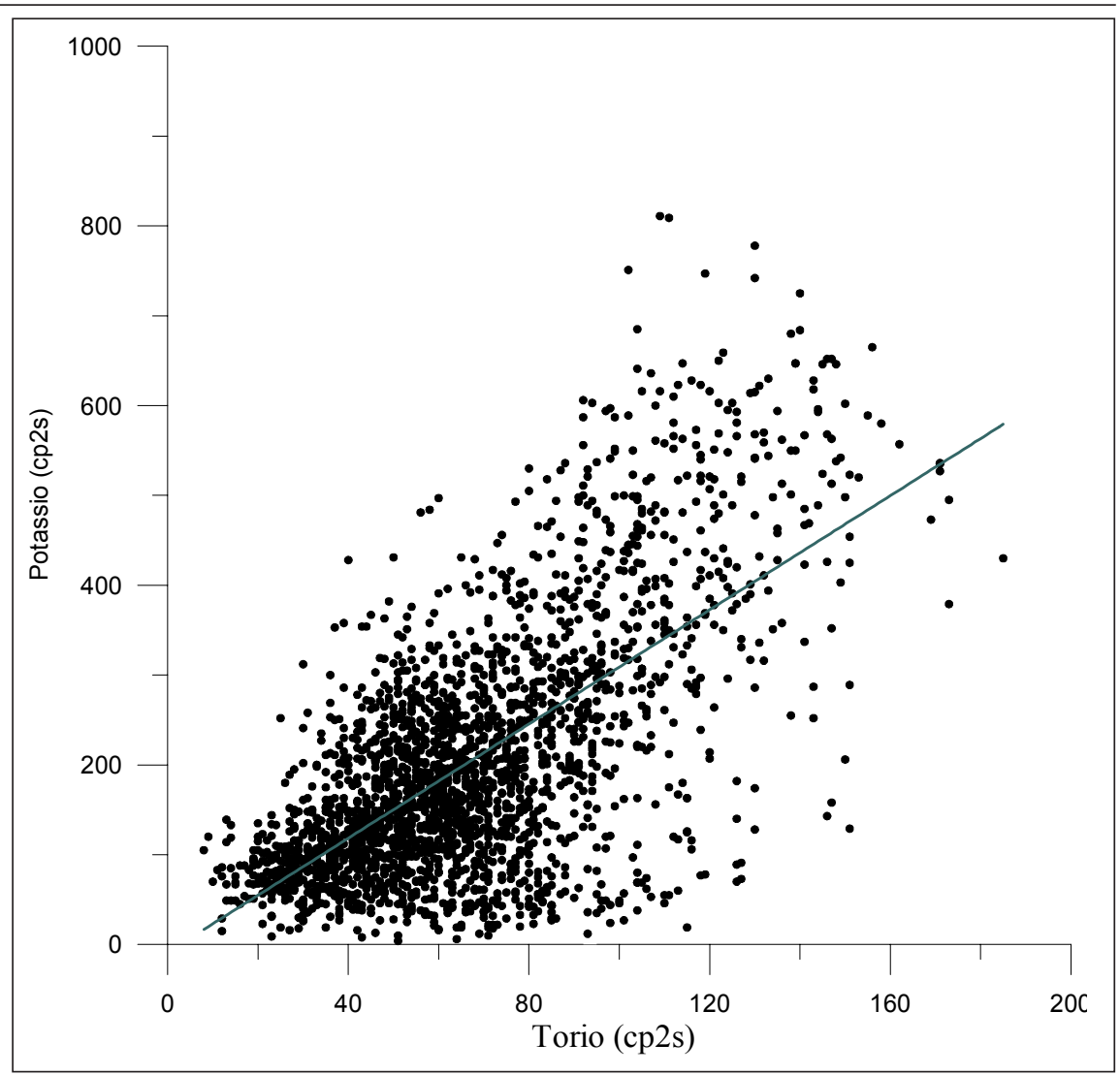

Figura 2 - Relação potássio x tório para os dados da região do Complexo Bossoroca.

Tabela 2 - Principais unidades litoestratigráficas da região do Complexo Bossoroca e seus principais domínios.

\begin{tabular}{c|c}
\hline Unidades Litoestratigráficas & Domínios Litoestratigráficos \\
\hline Cobertura Sedimentar Bacia do Paraná & 11 e 12 \\
\hline $\begin{array}{c}\text { Coberturas Sedimentares e } \\
\text { Vulcanossedimentares Bacia do } \\
\text { Camaquã }\end{array}$ & 10 \\
\hline Granito São Sepé & 8 \\
\hline Granito Cerro da Cria & 6 \\
\hline Granito Ramada & 7 \\
\hline Rincão dos Coqueiros & 9 \\
\hline Complexo Cambaí & 2 \\
\hline Seqüência Arroio Lajeadinho & $1 \mathrm{~b}$ e 1c \\
\hline Seqüência Campestre & 4 \\
\hline Complexo Pedras Pretas & 5 \\
\hline Gabro Mata Grande & 11 \\
\hline Formação Passo Feio & $1 \mathrm{~b}$ \\
\hline
\end{tabular}




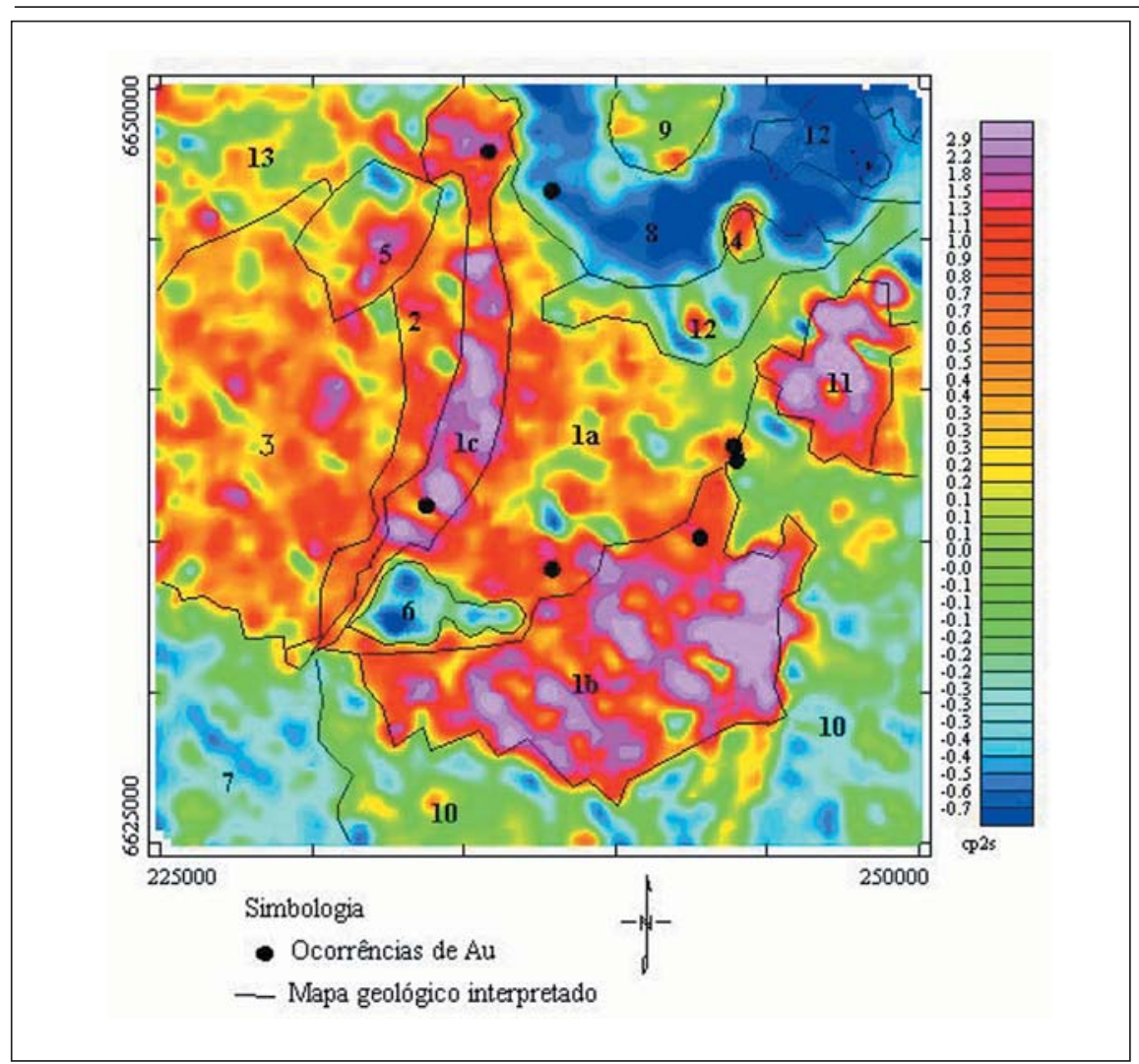

Figura 3 - Potássio anômalo para os dados da região do Complexo Bossoroca. Os contornos indicam as unidades litoestratigráficas (ver Tabela 2).

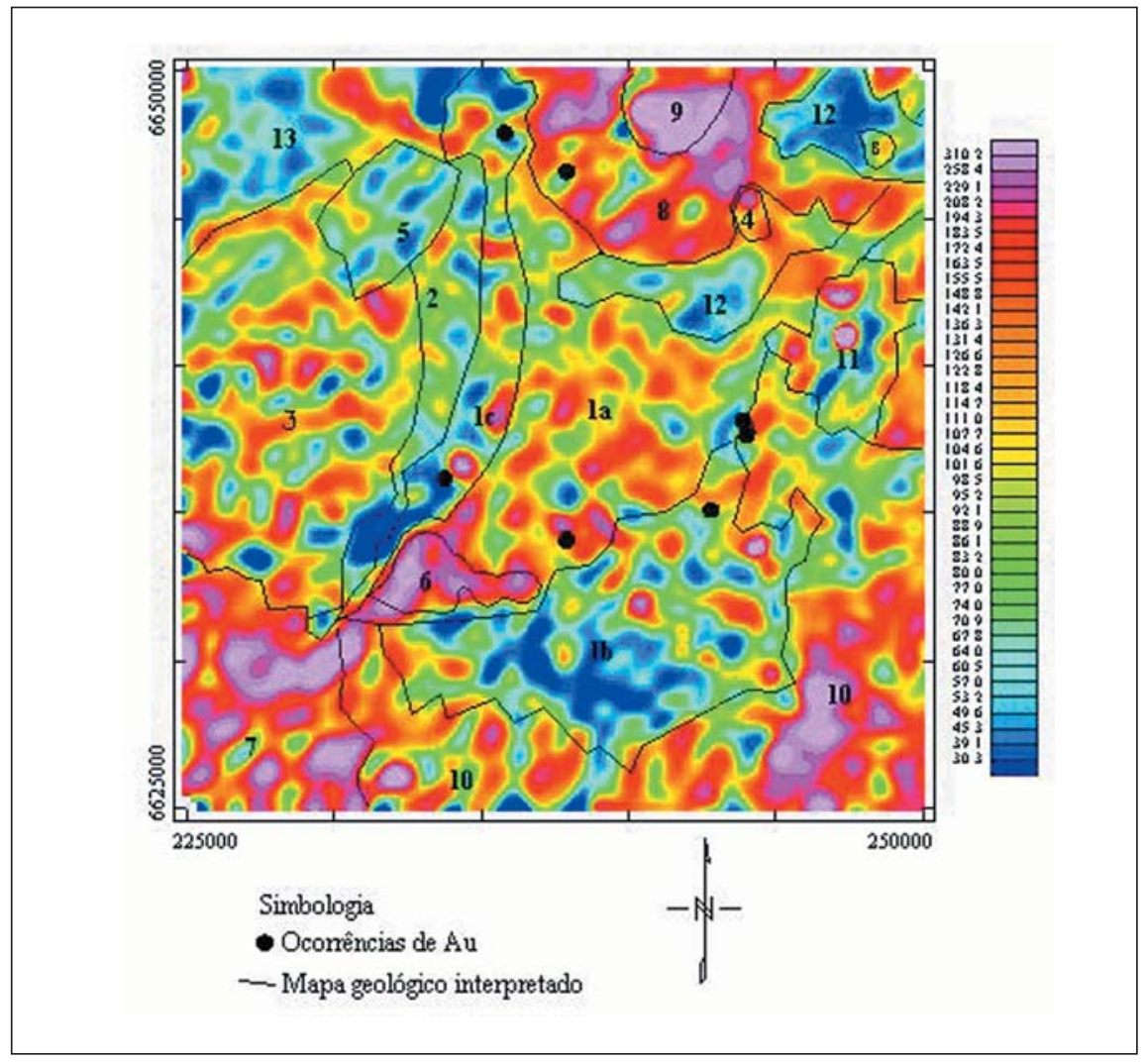

Figura 4 - Mapa do parâmetro F para os dados da região do Complexo Bossoroca. Os contornos indicam as unidades litoestratigráficas (ver Tabela 2). onde $e T h$ e $e U$ correspondem aos isótopos mais energéticos emitidos pelos seus isótopos filhos tálio $\left({ }^{208} \mathrm{Tl}\right)$ e bismuto $\left({ }^{214} \mathrm{Bi}\right)$, respectivamente (Dickson \& Scott, 1997).

Corpos magnéticos são originalmente mais profundos na porção leste.

\section{Interpretação dos resultados}

O potássio anômalo foi estimado para toda área de estudo e foi comparado ao mapa de domínios a fim de se ressaltarem e se correlacionarem as anomalias com as unidades geológicas (Figura $3)$. Nota-se que todos os domínios que representam as rochas graníticas $(8,6 \mathrm{e}$ 7) apresentam valores baixos e que as ocorrências auríferas, exceto a ocorrência encontrada na região do Granito São Sepé, encontram-se nos valores elevados de potássio anômalo. Algumas regiões dos domínios 10 e 12, correspondentes à bacia do Camaquã e Paraná, respectivamente, também, possuem valores baixos, bem como a região central do domínio 1a, pertencentes à Seqüência Campestre.

O parâmetro $F$ é utilizado para detectar regiões anômalas de potássio pelo antagonismo entre o tório e o potássio, o qual é típico de processos de alteração acompanhado por enriquecimento secundário de potássio. Os valores baixos representam as anomalias de tório, enquanto que altos valores, anomalias de potássio (Figura 4).

Estudos geoquímicos feitos por Koppe (1990) indicam que as razões $\mathrm{K}_{2} \mathrm{O} / \mathrm{Na}_{2} \mathrm{O}$ têm valores menores do que um, para os metatufos grossos, grafitosos, lapilíticos e finos da Seqüência Campestre, onde a ocorrência aurífera estaria associada a baixos valores de potássio. Verifica-se a presença dessa ocorrência tendendo à proximidade de valores baixos e também de valores altos, no domínio 1c, assim como a ocorrência Passo da Juliana, ao norte desse domínio. Regiões com valores baixos próximos de valores altos, portanto, nas quebras de relevo, podem servir de guia prospectivo para o domínio 1 . 


\section{Conclusões e recomendações}

As técnicas de processamento aerogamaespectrométricas utilizadas na avaliação de alterações hidrotermais foram positivas relacionando áreas anômalas como guias prospectivos para exploração mineral regional.

No mapa de parâmetro $F$, existem "quebras" de relevo radiométricos, que pode ser indicativo de mineralização.

Devido à diversidade geológica do Complexo Bossoroca foi difícil a separação entre fenômenos litológicos de zonas hidrotermais por meio de potássio anômalo. $\mathrm{O}$ espaçamento original de $1 \mathrm{~km}$ não permite o detalhamento maior das feições e provoca o espalhamento das anomalias (Pires, 1995).

Para potássio anômalo Carvalho (1999) justifica que o método pode ser mais bem aplicado em unidades rochosas individualizadas, de modo que possa ser esperada uma homogeneidade do potássio em relação ao tório. Quanto maior for a dispersão dos dados, mais ineficaz será a separação entre as concentrações litológicas de potássio e aquelas realmente anômalas.
Esse problema poderá ser resolvido num futuro aerolevantamento diminuindo o espaçamento entre as linhas de vôo.

\section{Referências bibliográficas}

AlmeidA, F. F. M., HASUi, Y. O PréCambriano do Brasil. São Paulo: E. Blücher, 1984. 374p.

BLUM, M. L. B. Processamento e interpretação de dados de geofísica aérea no Brasil Central e sua aplicação à geologia regional e à prospecção mineral. Brasília: Instituto de Geociências, Universidade de Brasília, 1999. 113p. (Tese de Doutorado).

CARVALHO, M. T. N. Integração de dados geológicos, geofísicos e geoquímicos aplicada à prospecção de ouro nos Greenstones Belts de Pilar de Goiás e Guarinos, $\boldsymbol{G} \boldsymbol{O}$. Brasília: Instituto de Geociências, Universidade de Brasília, 1999. 190 p. (Tese de Mestrado).

DICKSON, B. L., SCOTT, K. M. Interpretation of aerial gamma ray surveys - adding the geochemical factors. AGSO Journal of Australian Geology, v. 68, n.2, p. 145-160, 1973.

FORNAZZARI, L. N., FERREIRA, F.J.F., CAMPOS, A.F. Gamaespectrometria aplicada à prospecção de ouro na Folha Botuverá-SC. In: CONGRESSO INTERNACIONAL DA SOCIEDADE BRASILEIRA DE GEOFÍSICA, 7, Salvador. Proceedings... p. 621-624, 2001. JACKSON, V. N., RAMOS, V.A., TERRY, S. A., ZUZEK, A. B. Projeto aerogeofísico
Camaquã, Estado do Rio Grande do Sul. Porto Alegre: Texas Instruments, DNPM/ CPRM/CNEN, 1973. 208 p.

KOPPE, J. C. Metalogênese do ouro da Mina da Bossoroca, São Sepé, RS. Porto Alegre: Instituto de Geociências, UFRGS, 1990. 289 p. (Tese de Doutorado).

MACHADO, N., KOPPE, J. C., HARTMANN, L.A. A late proterozoic $\mathrm{U}-\mathrm{Pb}$ age for the Bossoroca Belt, Rio Grande do Sul, Brazil. Journal of South Americam Earth Sciences, v. 3, n.2/3, p. 87-90, 1990.

OSTROSVSKIY, E. Ya., Antagonism of radioative elements in wallrock alterations fields and its use in aerogamma spectrometric prospecting. International Geology Review, 17, p. 461468, 1973.

PIRES, A. C. B. Identificação geofísica de áreas de alteração hidrotermal, Crixás-Guarinos, Goiás. Revista Brasileira de Geociências, n.25, v. 1, p. 61-68, 1995.

PORCHER, C. A. Programa Levantamentos Geológicos Básicos do Brasil. Cachoeira do Sul. Folha 1:250.000. Estado do Rio Grande do Sul. CPRM, 2000. http:// www.cprm.gov.br/geo/csul.html

PRICHYSTAL, A., GNOJEK, I. A new zinc mineralization detected by airbone gammaray spectrometry in northern Moravia (Czechoslovakia). Geoexploration, n. 23, p.491-502, 1985.

REMUS, M. V. D., Metalogênese do cobre e evolução crustal da região de Caçapava do $\boldsymbol{S u l}, \boldsymbol{R S}$. Instituto de Geociências, UFRGS, 1998. (Tese de Doutorado em Geociências).

Artigo recebido em 28/08/2002 e aprovado em 21/12/2003.

\section{Assinar e publicar na REM é uma decisão inteligente.}

$* * * * * *$

REM

68 anos divulgando CIÊNCIA

$* * * * * *$ 